\title{
PENGARUH PENERAPAN GOOD GOVERNANCE TERHADAP KINERJA PELAYANAN PUBLIK, BUDAYA ORGANISASI DAN LINGKUNGAN EKSTERNAL SEBAGAI PEMODERASI.
}

\author{
Muhammad Dahlan', dan Asep Sumaryana ${ }^{2}$ \\ ${ }^{1}$ Fakulatas Ekonomi dan Bisnis Universitas Padjadjaran \\ ${ }^{2}$ Fakultas Ilmu Sosial dan Ilmu Politik Universitas Padjadjaran \\ E-mail: dahlanm2004@yahoo.com
}

\begin{abstract}
ABSTRAK: Penelitian ini bertujuan untuk menganalisis pengaruh budaya organisasi dan lingkungan eksternal terhadap hubungan antara penerapan prinsip-prinsip Good Governance dan kinerja pelayanan publik. Faktor budaya dan lingkungan eksternal menjadi penting di Kantor Kecamatan Kota Bandung, karena siapapun aparatur pemerintah jika golongan dan jabatannya sama akan menerima penghasilan yang sama meskipun diantara mereka beban kerjanya berbeda. Penelitian menggunakan metode eksplanatori yang artinya menjelaskan sebab dan akibat dari teori yang digunakan dalam menguji permasalahannya. Metode ini digunakan dengan pertimbangan yaitu selama proses pengumpulan data, analisis dan penarikan kesimpulan, peneliti melakukan konfirmasi kembali antara teori dengan hasil penelitian yang dihasilkan. Pengumpulan data menggunakan kuesioner dan dilaksanakan di 30 Kantor Kecamatan Kota Badung. Hasil penelitian menunjukan budaya organisasi dan lingkungan eksternal bukan sebagai variabel pemoderasi terhadap hubungan antara penerapan good governance dan kinerja unit pelayanan publik. Hal ini terlihat dari hasil tes tahap satu menunjukan variabel penerapan good governance berpengaruh positif dan signifikan terhadap kinerja pelayanan publik. Kemudian pada tes tahap kedua menunjukan variabel budaya organisasi dan lingkungan eksternal tidak berpengaruh terhadap kinerja pelayanan publik. Artinya budaya organisasi dan kondisi lingkungan eksternal belum menjadi faktor pendorong layanan publik karena mereka bekerja mengikuti aturan dan kebijakan formal yang berlaku.
\end{abstract}

Kata kunci: budaya organisasi, lingkungan eksternal, good governance dan kinerja unit pelayanan publik.

\section{THE EFFECT OF ORGANIZATIONAL CULTURE AND EXTERNAL ENVIRONMENTAL ON THE RELATIONSHIP BETWEEN GOOD GOVERNANCE AND PUBLIC PERFORMANCE.}

\begin{abstract}
The perpose of this research is the effect of good governance on public unit performance, with the organizations culture and perceived environmental uncertainty as a moderating variable. The organizations culture and perceived environmental uncertainty factors were important, because who are personnal and load job description defferent will be he receipt tax home pay were the same. This research were used explanatory research, because we are perpose to explanation relationship and effect of the variable construck. Collection of data were used quesionair and spacial design for this research. the unit analysis are 30 Kantor Kecamatan in Bandung Governmantal. Each of unit analysis we are expected as 5 respondent, so we have 150 respondent. Based on the research indicate that the effect of the organizations culture and perceived environmental uncertainty variable were not as moderating variable on the relationship between good governance and public unit performance. the third tested indicated the organizations culture and perceived environmental uncertainty variable is not effect on the public unit performance. And then the organizations culture and perceived environmental uncertaintyvariable were didn't effect on the public services and didn't factors as a motivator for personnel to encurege public services at goverrmental sectors.
\end{abstract}

Key words: Organizations culture, perceived environmental uncertainty, good governance, public unit performance, and moderating variable.

\section{PENDAHULUAN}

Penelitian ini menitik beratkan pada sejauhmana pelayanan publik telah dilayani. Indikator keberhasilan diukur dengan menggunakan Indek Kepuasan Masyarakat (IKM). Visi Pemerintah Kota Bandung yaitu: Terwujudnya Kota Bandung Yang Unggul, Nyaman Dan Sejahtera.

Menjadi yang terbaik dan terdepan dengan mempertahankan pencapaian sebelumnya serta menjadi contoh bagi daerah lain dalam upaya terobosan perubahan bagi kenyamanan dan kesejahteraan warga Kota Bandung. Terciptanya suatu kondisi dimana kualitas lingkungan terpelihara dengan baik melalui sinergitas lintas sektor sehingga dapat memberikan kesegaran dan kesejukan bagi penghuninya kota yang nyaman adalah suatu kondisi dimana berbagai kebutuhan dasar manusia seperti tanah, air, dan udara terpenuhi dengan baik sehingga nyaman untuk ditinggali serta ruang-ruang kota dan infrastruktur pendukungnya responsif terhadap berbagai aktifitas dan perilaku penghuninya. Melalui peningkatan partisipasi dan kerjasama seluruh lapisan masyarakat, agar dapat memfungsikan diri sebagai hamba dan wakil Tuhan di bumi.

Kesejahteraan yang ingin diwujudkan merupakan kesejahteraan yang berbasis pada ketahanan keluarga 
dan lingkungan sebagai dasar pengokohan sosial. Masyarakat sejahtera tidak hanya dalam konteks lahiriah dan materi saja, melainkan juga sejahtera jiwa dan batiniah. Kesejahteraan dalam artinya yang sejati adalah keseimbangan hidup yang merupakan buah dari kemampuan seseorang untuk memenuhi tuntutan dasar seluruh dimensi dirinya, meliputi rohani, akal, dan jasad. Kesatuan elemen ini diharapkan mampu saling berinteraksi dalam melahirkan masa depan yang cerah, adil dan makmur. Keterpaduan antara sejahtera lahiriah dan batiniah adalah manifestasi dari sejahtera yang paripurna. Kesejahteraan yang seperti inilah yang akan membentuk kepecayaan diri yang tinggi pada masyarakat kota Bandung untuk mencapai kualitas kehidupan yang semakin baik, hingga menjadi teladan bagi kota lainnya.

Selanjutna misi Kota Bandung mewujudkan Bandung nyaman melalui perencanaan tata ruang, pembangunan infrastruktur serta pengendalian pemanfaatan ruang yang berkualitas dan berwawasan lingkungan. Mengahdirkan tata kelola pemerintahan yang akuntabel, bersih dan melayani. Membangun masyarakat yang mandiri, berkualitas dan berdaya saing, dan membangunan perekonomian yang kokoh, maju dan berkeadilan (UU Nomor 25/2009 adalah: Misi pertama adalah Mewujudkan Bandung nyaman melalui perencanaan tataruang, pembangunan infrastruktur serta pengendalian pemanfaatan ruang yang berkualitas dan berwawasan lingkungan. Dimaksudkan untuk menciptakan kenyamanan bagi seluruh warga Kota Bandung melalui pembangunan infrastruktur yang berkualitasdenganmemperhatikandayatampungdandaya dukung lingkungan; Misi kedua, mewujudkan Bandung nyaman melalui perencanaan tataruang, pembangunan infrastruktur serta pengendalian pemanfaatan ruang yang berkualitas dan berwawasan lingkungan. Dimaksudkan untuk menciptakan kenyamanan bagi seluruh warga Kota Bandung melalui pembangunan infrastruktur yang berkualitas dengan memperhatikan daya tampung dan daya dukung lingkungan; Misi ketiga, Membangun masyarakat yang mandiri, berkualitas dan berdaya saing. Dimaksudkan untuk mewujudkan warga Kota Bandung yang sehat, cerdas, dan berbudaya yang bercirikan meningkatnya ketahanan keluarga, menurunnya jumlah Penyandang Masalah Kesejahteraan Sosial (PMKS), tingginya peran pemuda dalam pembangunan, meningkatnya prestasi olah raga tingkat nasional dan internasional, terpeliharanya seni dan warisan budaya; Misi terakhir adalah Membangun perekonomian yang kokoh, maju, dan berkeadilan. Dimaksudkan untuk meningkatkan kesempatan kerja dan perlindungan tenaga kerja, menciptakan iklim usaha yang kondusif, mengembangkan koperasi dan UMKM, mewujudkan pariwisata yang berdaya saing dan bekelanjutan, Meningkatkan ketahanan pangan. Mengembangkan sistem pembiayaan kota terpadu.

Untuk mewujudkan Visi dan Misi tersebut di atas,
Pemerintah Kota telah menyusun juga rencana stratejik yang dikenal dengan nama arah kebijakan pembangunan terdiri dari (1) Mengupayakan perluasan dan pemerataan kesempatan memperoleh pendidikan, kesehatan serta pelayanan keagamaan bagi seluruh masyarakat. (2) Mengupayakan peningkatan kegiatan perekonomian kota berbasis potensi daerah. (3) Mendorong peningkatan integrasi dan ketahanan sosial masyarakat serta peningkatan rasa kepedulian sosial masyarakat. (4) Mengupayakan perluasan dan pemerataan pelayanan prasarana dan sarana kota serta pengembangan aktivitas kota yang sesuai dengan daya dukung dan daya tampung lingkungan. (5) Mengupayakan terjadinya peningkatan pelayanan pemerintahan kepada masyarakat dan peningkatan partisipasi masyarakat dalam pelaksanaan serta pengendalian dan pengawasan pembangunan kota. Dan (6) Mendorong pertumbuhan dan pembangunan potensi pembiayaan pembangunan kota.

Untuk lebih memastikan bahwa pembangunan dan pelayanan prima kepada masyarakat dapat tercapai dan sesuai harapan, maka tak tanggung-tanggung untuk mendukung Visi dan Misi, Pemerintah Kota Bandung mengusung tujuh (7) program prioritas Kota Bandung yaitu:

1. Bidang Pendidikan, terwujudnya Bandung cerdas yang diharapkan agar wajib belajar sampai ke tingkat SLTA.

2. Bidang Kesehatan, diharapkan terwujudnya Bandung sehat.

3. Bidang Kemakmuran, diharapkan akan tercapainya laju pertumbuhan ekonomi yang berkesinambungan.

4. Bidang Lingkungan Hidup, gerakan penghijauan, hemat dan menabung air, gerakan cikapundung bersih, gerakan sejuta bunga untuk bandung, gerakan udara bersih, gerakan P4LH (penanaman, pembibitan, pemeliharaan dan pengawasan lingkungan hidup) dan program K3 (ketertiban, kebersihan, dan keindahan) serta muatan lokal lingkungan hidup bagi anak sekolah.

5. Pembinaan Seni dan Budaya, dengan sasaran terwujudnya Bandung kota seni dan budaya.

6. Pembinaan dan Prestasi Olahraga, sasarannya diharapkan terwujudnya Bandung berprestasi olahraga.

7. Pembinaan Kerukunan Umat Hidup beragama, dengan sasaran terwujudnya Bandung agamis.

Salah satu Misi Pemerintah Kota Bandung adalah menghadirkan tata kelola pemerintahan yang akuntabel, bersih dan melayani. Tata kelola pemerintah yang baik merupakan ciri dasar dari penerapan konsep Good Governance. Menerapkan praktik good governance dapat dilakukan secara bertahap sesuai dengan kapasitas pemerintah, masyarakat sipil, dan mekanisme pasar. Salah satu pilihan strategis untuk menerapkan good governance adalah melalui penyelenggaraan pelayanan publik. 
Ada beberapa pertimbangan mengapa pelayanan publik menjadi strategis untuk memulai menerapkan good governance. Pelayanan publik sebagai penggerak utama juga dianggap penting oleh semua aktor dari unsur good governance. Para pejabat publik, unsurunsur dalam masyarakat sipil dan dunia usaha samasama memiliki kepentingan terhadap perbaikan kinerja pelayanan publik (UNDP, 1997).

Pembangunan ekonomi, pemanfaatan sistem teknologi informasi, pembangunan sosio-politik, dan produk hukum lembaga legislatif belum berdampak langsung terhadap peningkatan kemakmuran masyarakat.

Administrasi publik-pemerintahan kepada masyarakat yang lebih menonjol adalah peran eksekutif dan legislatif (Rosenbloom dan Kravchuk, 2005). Eksekutif (pemerintah) bertindak sebagai yang menjalankan pemerintahan dalam melayani masyarakat, sedangkan legislatif sebagai yang pengawas dan menghasilkan berbagai produk hukum dan peraturan yang berfungsi sebagai acuan pemerintah dalam melaksanakan tugasnya. Hal ini terlihat pada aspek constitutions (undang-undang dan peraturan lainnya), the public interest (kebutuhan masyarakat sarana dan prasaran serta pelayanan publik), soveregnty (partai politik dan organisasi sosial), dan lainlain.

Robbins dan Coulter (2009) dan Daft (2007) menjelaskan faktor lingkungan eksternal dan budaya organisasi dapat memberikan dampak positif dalam membangun organisasi dan kinerjanya jika dikelola dengan baik dan konsisten serta dapat juga berdampak negatif jika pengelolaannya tidak tepat sasaran, sehingga roda organisasi akan berjalan secara tidak efisien dan efektif. Begitu juga menurut Wheelen dan Hunger (2012) dalam mendesain organisasi dan perencanaan jangka panjang sebaik mengaju kepada strategi organisasi yang berlaku.

Budaya organisasi merupakan perpaduan budaya jaringan, budaya upahan, budaya fragmen dan budaya Komunal. Kesemuanya berpadu secara harmonis atau ada pertalian antara satu dengan yang lainnya. Saling memahami satu dengan yang lainnya dalam kehidupan para pegawainya tampak terlihat dalam keseharian karena budaya ditafsirkan sebagai nilai dan kepercayaan. Dengan espaused dan enacted melekat pada kehidupan birokrasi yang mengadopsi kultur lokal piil pasenggiri sehingga kinerja birokrasi dan interaksi menjadi lebih baik diantara para pegawai (Kausar, 2013).

Pandangan lainnya, seperti hasil penelitian Gordon dan Narayanan (1984), Govindarajan (1986), Otley (1980) dan Hayes (1977) menyatakan perubahan lingkungan eksternal budaya organisasi merupakan variabel moderasi yang dapat berfungsi memperlemah dan memperkuat hubungan antara perencanaan dan pengelolaan organisasi dan kinerja. Namun, penelitian ini dilakukan pada perusahaan profit motive.

Dengan demikian, baik organisasi privat maupun publik sebaiknya selalu mempertimbangkan faktor- faktor yang mempengaruhi tercapai tidaknya tujuan yang ditetapkan. Misalnya faktor lingkungan eksternal dan budaya organisasi. Karena faktor tersebut dapat memperkuat atau memperlemah hubungan antara efektivitas good governance dan kinerja organisasi. Pemerintah Kota Bandung telah menyusun visi, misi dan tujuannya dengan harapan kinerja pelayanan publik meningkat dan sesuai dengan harapan masyarakat Kota Bandung.

Berdasarkan uraian di atas, maka hipotesis penelitian yang diajukan seperti berikut:

Ha: terdapat pengaruh positif dan signifikan variabel perubahan lingkungan eksternal Dan budaya organisasi terhadap hubungan antara penerapan good governance dan kinerja pelayanan publik.

\section{METODE}

\section{Data dan Metode Penelitian}

Ruang lingkup penelitian ini adalah Kantor Kecamatan (30 kantor kecamatan). Pengumpulan data menggunakan quesioner menggunakan 5 skala-Likert (Sekaran dan Bougie, 2010). Setiap kantor dipilih secara acak 5 orang, sehingga jumlah responden 150 .

Metode yang digunakan yaitu selama proses pengumpulan data, penelitimelakukan wawancara dengan beberapan responden terpilih untuk mengkonfirmasi kembali data yang ada di kuesioner dan menanyakan lebih lanjut atas implementasi UU Nomor 25 Tahun 2009 tengan Pelayanan Publik.

Alat analisis data menggunakan regresi berganda (Cooper dan Schindler, 2006; Hair, et all, 2005). Metode regresi sederhana digunakan untuk menguji pengaruh faktor budaya organisasi dan lingkungan eksternal sebagai variabel pemoderasi terhadap hubungan antara penerapan Good Governance dan kinerja unit pelayanan publik.

\section{Operasionalisasi Variabel Penelitian.}

Operasionalisasi variabel penelitian mengacu kepada UU Nomor 25 Tahun 2009 tentang Pelayanan publik dan Peraturan Menteri Pendayagunaan Aparatur Negara dan Reformasi Birokrasi Nomor 38 Tahun 2012 tentang Pedoman PenilaianKinerjaUnitPelayananPublik. Indikator pelayanan publik dalam penelitian ini adalah penilaian dibagi atas 5 (lima) indikator penilaian yaitu: kepuasan (satisfaction), ketepatan waktu penyelesaian, kepercayaan masyarakat unit layanan, pungutan biaya layanan dan kualitas pelayanan publik. Indikator Good Governance adalah 6 indikator yaitu: kapabilitas petugas/ aparatur layanan, tanggungjawab petugas, keterbukaan informasi, penerapan sistem penjaminan mutu, kejelasan/ kemudahan prosedur layanan, dan sarana dan prasaran pendukung.

Sedangkan Indikator budaya organisasi adalah 4 indikator yaitu: kedisiplinan petugas/aparatur, 
keadilan pelayanan, kesopanan dan keramahan petugas, dan loyalitas petugas layanan. Sementara indikator lingkungan eksternal adalah 4 indikator yaitu: perubahan peraturan dan perundang-undangan, pertumbuhan ekonomi, pemanfaatn kemajuan teknologi informasi, dan perubahan sosio-politik Indonesia.

Berdasarkan dimensi dan indikator variabel penelitian, maka dirumuskan struktur analisis regresi pemoderasi hubungan antar variabel yang diteliti seperti berikut:

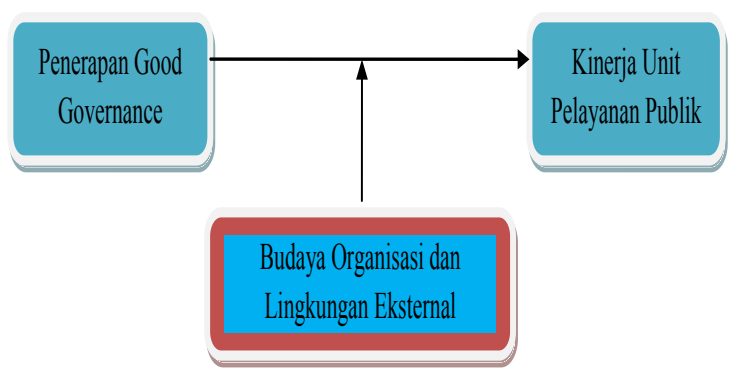

Gambar 1. Rancangan Model Penelitian.

Penilaian kinerja unit pelayanan publik menggunakan angket/kuesioner yang diisi oleh masyarakat. Data responden yang terpilih sebanyak 158 responden yang tersebar di 30 kecamatan terbagi atas jenis kelamin laki-laki $124(78,50 \%)$ dan 34 (21,50\%) perempuan. Berdasarkan jenis pekerjaan Ibu Rumah Tangga 17 (10,76\%), Karyawan PNS dan
Swasta 77 (48,73\%), dan Wiraswasta 64 (40,51\%), serta jenjang pendidikan adalah Sekolah Menengah Atas 107 (67,72\%), Diploma 20 (12,66\%), dan Sarjana (S1-S2-S3) sebanyak 31(19,62\%).

Kuesioner berisi 19 (sembilan belas) pertanyaan yang berkaitan dengan aspek pelayanan, good governance, budaya organisasi dan perubahan lingkungan eksternal. Semua pertanyan berhubungan dengan capaian kinerja unit pelayanan publik dan faktorfaktor yang mempengaruhi kinerja unit pelayanan publik. Pertanyaaan dirumuskan dalam bentuk skala Likert 1 s.d. 5 yaitu 1 = sangat kurang, 2 = kurang, $3=$ cukup, $4=$ baik/lebih dari cukup, dan $5=$ sangat baik. Hasil tabulasi data atas 158 responden terpilih menunjukan skor rata-rata tertimbang seperti berikut:

Sebelum analisis regresi dilaksanakan, terlebih dahulu data yang terkumpul dari kuesioner diuji validitas dan reliabilitas data, ukurannya adalah skor komponen analisis faktor dan crombach alfa. Hasil uji dapat disimpulkan yaitu data valid dan reliabel (Nunnaly, 1978; Kaiser dan Rice, 1974). Hasilnya seperti berikut:

Berdasarkan tabel 2 hasil analisis hubungan menunjukan variabel kinerja pelayanan publik, penerapan good governance, budaya organisasi dan lingkungan eksternal menunjukan saling berkorelasi atau berhubungan satu sama yang lainnya adalah signifikan.

Tabel 1. Rata-rata tertimbang indikator penelitian

\begin{tabular}{llll}
\hline Kepuasan layanan & 3,24 & Ketepatan waktu penyelesaian & 2,94 \\
Kepercayaan masyarakat & 3,54 & Pungutan biaya & 5 \\
Kualitas layanan & 3,22 & Kapabilitas petugas/pegawai & 3,5 \\
Tanggungjawab & 3,55 & Keterbukaan informasi & 3,57 \\
Sistem penjaminan mutu & 3,45 & Kejelasan prosedur layanan & 3,41 \\
Sarana dan prasarana & 3,45 & Kedisiplinan pegawai & 3,46 \\
Keadilan layanan & 3,58 & Kesopanan/keramahan pegawai & 3,77 \\
Loyalitas petugas & 3,47 & Kontribusi produk hukun & 3,55 \\
Kontribusi pertumbuhan ekonomi & 3,39 & Kontribusi teknologi informasi & 3,35 \\
Kontribusi sosio-politik & 3,27 & & \\
\hline
\end{tabular}

Tabel 2. Korelasi Pearson antar variabel $(n=158)$

\begin{tabular}{cccccccccc}
\hline & Y & X1 & X2 & X3 & Min & Max & Mean & Std & $\begin{array}{c}\text { C. } \\
\text { Alpha }\end{array}$ \\
\hline Kinerja Pelayanan Publik (Y) & 1 & & & & 11.00 & 25.00 & 17.94 & 2.56 & 0.874 \\
Penerapan Good Governance (X1). & $721^{* *}$ & 1 & & & 9.00 & 30.00 & 20.92 & 3.48 & 0.744 \\
Budaya organisasi (X2) & $.577^{* *}$ & $.751^{* *}$ & 1 & & 7.00 & 20.00 & 14.29 & 2.41 & 0.816 \\
Lingkungan Eksternal (X3) & $.514^{* *}$ & $.669^{* *}$ & $.632^{* *}$ & 1 & 4.00 & 20.00 & 13.56 & 2.69 & 0.794
\end{tabular}

Level Signifikansi: $* * p=0.001$ 


\section{HASIL DAN PEMBAHASAN}

\section{Analisis pengaruh variabel independen terhadap variabel dependen}

Hasil analisis pada tabel 3 menunjukan penerapan good governance terhadap kinerja pelayanan publik Pemerintah Kota Bandung adalah berpengaruh positif dan signifikan. Namun, budaya organisasi dan lingkungan eksternal teridentifikasi tidak berpengaruh terhadap pelayanan publik.

\section{Analisis Pengaruh Pemoderasi Variabel Ling- kungan Eksternal.}

Analisis berikut untuk menguji pengaruh varibel pemoderasi lingkungan eksternal sebelum dan sesudah interaksi dengan variabel penerapan good governance terhadap kinerja pelayanan publik.

Berdasarkan tabel 4 di atas, hasil analisis regresi pemoderasi menunjukan secara bersama-sama variabel penerapan good governance, dan lingkungan eksternal berpengaruh positif dan signifikan terhadap kinerja pelayanan publik. Secara parsial hanya variabel penerapan good governance berpengaruh positif dan signifikan terhadap kinerja pelayanan publik. Namun, variabel interaksi good governance dengan lingkungan eksternal tidak berpengaruh terhadap hubungan antara penerapan good governance dan kinerja pelayanan publik. Persamaan regresi pemoderasi seperti berikut: KINERJA $=7.374+0,468 \mathrm{GGOVN}+0,003 \mathrm{GGOVN}$ $*$ LEKS $+\mathrm{e}_{1}$

\section{Analisis Pengaruh Pemoderasi Variabel Budaya Organisasi.}

Analisis berikut untuk menguji pengaruh varibel pemoderasi budaya organisasi sebelum dan sesudah interaksi dengan variabel penerapan good governance terhadap kinerja pelayanan publik.

Berdasarkan tabel 5 hasil analisis regresi pemoderasi menunjukan secara bersama-sama variabel penerapan good governance, dan budaya organisasi berpengaruh positif dan signifikan terhadap kinerja pelayanan publik. Secara parsial hanya variabel penerapan good governance berpengaruh positif dan signifikan terhadap kinerja pelayanan publik. Namun, variabel interaksi good governance dengan budaya organisasi tidak berpengaruh terhadap hubungan antara penerapan good governance dan kinerja pelayanan publik. Persamaan regresi pemoderasi seperti berikut:

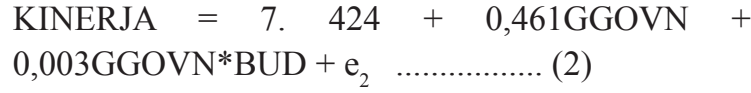

Hasil uji pengaruh pemoderasi menunjukan penerapan good governance berpengaruh positif dan signifikan terhadap kinerja unit pelayanan publik. Namun secara bersama-sama Budaya organisasi, lingkungan eksternal dan penerapan good governance berpengaruh positif dan signifikan terhadap kinerja unit pelayanan publik. Hal ini mendukung kesimpulan di atas karena ke-empat variabel tersebut memiliki hubungan yang positif dan signifikan dengan kinerja unit pelayanan publik.

Tabel 3. Besaran pengaruh koefisien beta terhadap kinerja pelayanan publik

\begin{tabular}{lcccccc}
\hline & R Square & F & Sig & $\begin{array}{c}\text { Unstandardized } \\
\text { Coefficients (B) }\end{array}$ & t & Sig \\
\hline Kinerja Pelayanan Publik (Y) & .524 & 56.532 & .000 & & & \\
Konstanta & & & & 6.486 & 6.998 & .000 \\
Penerapan Good Governance (X1) & & & & .473 & 7.068 & .000 \\
Budaya organisasi (X2) & & & .073 & .790 & .431 \\
Lingkungan Eksternal (X3) & & & & .038 & .515 & .607 \\
\hline
\end{tabular}

Tabel 4. Besaran pengaruh koefisien beta terhadap kinerja pelayanan publik

\begin{tabular}{|c|c|c|c|c|c|c|}
\hline & R Square & $\mathbf{F}$ & Sig & $\begin{array}{l}\text { Unstandardized } \\
\text { Coefficients (B) }\end{array}$ & $\mathbf{t}$ & Sig \\
\hline \multicolumn{7}{|l|}{ Sebelum interaksi: } \\
\hline Kinerja Pelayanan Publik (Y) & .520 & 169.293 & .000 & & & \\
\hline Konstanta & & & & 6.841 & 7.914 & .000 \\
\hline Penerapan Good Governance (X1) & & & & .530 & 13.011 & .000 \\
\hline \multicolumn{7}{|l|}{ Setelah interaksi: } \\
\hline Kinerja Pelayanan Publik (Y) & .522 & 84.763 & .000 & & & \\
\hline Konstanta & & & & 7.374 & 6.736 & .000 \\
\hline Penerapan Good Governance (X1) & & & & .468 & 5.326 & .000 \\
\hline Interaksi GGOVN*LEKS (X4) & & & & .003 & .795 & .428 \\
\hline
\end{tabular}


Tabel 5. Besaran pengaruh koefisien beta terhadap kinerja pelayanan publik

\begin{tabular}{|c|c|c|c|c|c|c|}
\hline & R Square & $\mathbf{F}$ & Sig & $\begin{array}{l}\text { Unstandardized } \\
\text { Coefficients (B) }\end{array}$ & $\mathbf{t}$ & Sig \\
\hline \multicolumn{7}{|l|}{ Sebelum interaksi: } \\
\hline Kinerja Pelayanan Publik (Y) & .520 & 169.293 & .000 & & & \\
\hline Konstanta & & & & 6.841 & 7.914 & .000 \\
\hline Penerapan Good Governance (X1) & & & & .530 & 13.611 & .000 \\
\hline \multicolumn{7}{|l|}{ Setelah interaksi: } \\
\hline Kinerja Pelayanan Publik (Y) & .522 & 84.635 & .000 & & & \\
\hline Konstanta & & & & 7.424 & 6.236 & .000 \\
\hline Penerapan Good Governance (X1) & & & & .461 & 4.353 & .000 \\
\hline Interaksi GGOVN*BUD (X5) & & & & .003 & .714 & .476 \\
\hline
\end{tabular}

Di lain pihak, budaya organisasi dan lingkungan eksternal bukan variabel pemoderasi atas hubungan antara penerapan good governance dan kinerja unit pelayanan publik, sehingga dapat disimpulkan bahwa model budaya organisasi yang diterapkan belum sesuai dengan untuk kantor Kecamatan Kota bandung. Disamping itu, aparatur kecamatan menganggap masalah perubahan lingkungan eksternal selama ini belum menjadi pertimbangan dalam bekerja melayani masyarakat. Ini juga membuktikan salah satu penyebab mengapa pelayanan publik kurang optimal.

Hasil penelitian ini tidak konsisten dengan hasil penelitian terdahulu (Gordon dan narayanan, 1984; Govindarajan, 1986; Otley, 1980, dan Hayes, 1977), sehingga Ha tidak dapat diterima. Dapat juga dikatakan bahwa aparatur Pemerintah Kota Bandung belum sepenuhnya memahami pentingnya penerapan nilainilai budaya organisasi yang baik serta merespon dengan seksama perubahan lingkungan eksternal dalam upaya meningkatkan kinerja pelayanan kepada masyarakat sebagaimana yang ditegaskan dalam teori ilmu manajemen (Daft, 2007; Robbins dan Coulter, 2009, dan Wheelen dan Hunger, 2012)

Budaya organisasi dan perubahan lingkungan Kota Bandung belum memberikan manfaat optimum dalam rangka peningkatan layanan publik. Oleh karena itu, diharapkan ada desain baru budaya organisasi. Pembangunan ekonomi, pemanfaatan sistem teknologi informasi saat ini, pembangunan sosio-politik, dan produk hukum anggota Dewan Perwakilan Rakyat Daerah seyagyanya diarahkan kepada terciptanya manfaat nyata bagi peningkatan kinerja unit pelayanan publik.

\section{SIMPULAN}

Berdasarkan hasil analisis regresi pemoderasi menunjukan secara bersama-sama variabel penerapan good governance, budaya organisasi dan lingkungan eksternal berpengaruh positif dan signifikan terhadap kinerja pelayanan publik. Namun secara parsial hanya variabel penerapan good governance berpengaruh positif dan signifikan terhadap kinerja pelayanan publik. Disamping itu, budaya organisasi dan lingkungan eksternal bukan sebagai variabel pemoderasi terhadap hubungan antara penerapan good governance dan kinerja unit pelayanan publik.

Aparatur pemerintah Kantor Kecamatan belum optimal melakukan reformasi birokrasi pelayanan publik dan kurang respon terhadap perubahan lingkungan eksternal yang begitu dahsyat saat ini. Pelayanan masyarakat secara umum telah sesuai dengan UndangUndang Nomor 25 Tahun 2009 tentang Pelayanan Publik, namun masih harus kerja keras lagi untuk memenuhi standar yang diinginkan masyarakat.

\section{DAFTAR PUSTAKA}

Cooper, D.R. dan Schindler, P.S. 2006. Business Research Methods. Ninth edition. New York: McGraw-Hill Company, Inc.

Daft, R.L. 2007. Management. $6^{\text {th }}$ Edition. Singapore: Thomson Learning.

Gordon, L.A. dan Narayanan, V.K. 1984. Management accounting systems, perceived environmental uncertainty and organization structure: an empirical investigation. Accounting, Organizations and Society 9(1): 33-47.

Hayes, D.C. 1977. The contingency theory of manageril accounting. The Accounting Review LII(1): 22-39.

Hair, J.F., Anderson, R.E. Tatham, R.L. dan Black, W.C. 2005. Multivariate Data Analysis. Sixth edition. New York: Prentice-Hall, Inc.

Kaiser, H,F. dan Rice, J. 1974. Little jiffy, mark IV. Educational and Psychological Measurement. 34: 111-117.

Kausar. 2013. Budaya Organisasi Pemerintahan Daerah Kabupaten Tulang Bawang Lampung. Sosiohumaniora. Volume 15, No. 1, Maret 2013 : 26 -34 
Peraturan Menteri Pendayagunaan Aparatur Negara dan Reformasi Birokrasi RI. No. 38 Tahun 2009 tentang Pedoman Penilaian Kinerja Unit Pelayanan Publik. Jakarta.

Govindarajan, V. 1986. Impact of participation in the budgetary process on managerial attitudes and performance: universalistic and contingency perspectives. Decision Science 17(4): 496-516.

Otley, D.T. 1980. The contingency theory of management accounting: achievement and prognosis. Accounting, Organizations and Society 5(4): 413-428.
Rosenbloom, D.H. dan Kravchuk, R.S. 2005. Public Administration: Understanding Management, Politics, and Law in the Public Sector. $6^{\text {th }}$ Edition. Boston USA: Mc-Graw Hill.

Robbins, S.P. dan Coulter, M. 2009. Management. $10^{\text {th }}$ Edition. New Jersey: Pearson Education, Inc.

Sekaran, U. dan Bougie, R. 2010. Research Methods for Business: A Skill Building Approach. Fifth edition. West Sussex: John Wiley \& Sons, Ltd.

Wheelen, T.L. dan Hunger, J.D. 2012. Strategic Management and Business Policy: Achieving sustainability. Thirdteenth edition. Boston: Prentice Hall. 